\title{
Searching for clover root weevil (Sitona lepidus) resistance/tolerance - A progress report
}

\author{
J.P.J. EERENS ${ }^{1}$, B.M. COOPER ${ }^{2}$, B.E. WILLOUGHBY ${ }^{1}$ and D.R. WOODFIELD ${ }^{3}$ \\ ${ }^{1}$ AgResearch Ruakura, Private Bag 3123, Hamilton \\ ${ }^{2}$ AgResearch, Kerikeri Research Station, P.O. Box 23, Kerikeri \\ ${ }^{3}$ AgResearch Grasslands, Private Bag 11008, Palmerston North \\ han.eerens@agresearch.co.nz
}

\begin{abstract}
The decimation of white clover in Waikato and Bay of Plenty pastures owing to the invasion clover root weevil (CRW) initiated an extensive screening of legume germplasm to identify plant material that could survive and remain productive under high CRW pressure. A total of 50000 plants from 275 lines and six species, were planted on seven commercial farms and evaluated for tolerance/ resistance to CRW under conventional farming practices. Plant productivity and level of CRW damage were both highest on white clover. Significant CRW damage was also observed on red clover and caucasian clover, but not on birdsfoot trefoil, lotus major or lucerne. However, the productivity under stock grazing of the latter three species was not sufficient to consider them suitable alternatives to white clover. Within the white clover lines there was encouraging variability in the level of CRW damage, and in the ratio of damage to shoot production. While root damage is of greater importance than shoot damage, the latter reflects CRW activity and egg deposition and is a good indicator of likely larval development and root damage. Factors such as farm type (dairy farms versus dry stock farms) had some influence on shoot production, but very little influence on CRW damage. Climatic conditions appeared to have strong influences on clover shoot production and CRW damage, with dry conditions from late spring to early autumn having a particularly suppressive effect on CRW damage and CRW population growth. Top performing lines have been selected from this screening and are currently being evaluated in more detail under high CRW pressure.
\end{abstract}

Keywords: clover, clover root weevil, plant screening, Sitona lepidus, tolerance, Trifolium repens

\section{Introduction}

The introduction of the clover root weevil (Sitona lepidus) (CRW) into New Zealand in the early 1990s exposed the New Zealand pastoral agriculture industry to a serious threat (Barratt et al. 1996). There was little published information applicable to New Zealand even though CRW can be found in North America and from the Arctic circle to the Mediterranean in Europe and east to the Indian subcontinent (Gerard et al. 1999). In many of the countries where CRW is endemic, several Sitona species compete for oviposition sites and food (Murray 1996). In most areas with similar environmental conditions to New Zealand, intensive pastoral farming is more biased towards grass monocultures with higher application rates of mineral nitrogen. In addition, various diseases, parasites and predators may suppress CRW populations in areas where it is endemic (Phillips et al. 2000).

New Zealand pastoral farmers predominantly use white clover (Trifolium repens) as a high quality feed and to partially or totally supply nitrogen. Clover levels in New Zealand pastures are high by world standards, creating a plentiful food supply for clover-feeding pests. There is only one other Sitona species in New Zealand, Sitona discoideus, which affects lucerne (Medicago sativa) but does not affect clover (Barratt et al. 1996).

The arrival of CRW in New Zealand created a favourable situation for this pest; suitable environmental conditions, virtually unlimited food supply, little competition and the potential to spread all over the country. The research programme implemented by AgResearch targeted three areas: Biological control (Phillips et al. 2000), pasture management options to minimise the impacts of CRW, and screening legumes to identify sources of tolerance/resistance to CRW. In this paper we report on progress in screening legumes.

\section{Materials and methods}

Seedlines available from the Margot Forde Germplasm Centre at Palmerston North were examined to select lines that potentially possessed tolerance/resistance. Many of the initial selections originated from outside New Zealand where CRW is endemic. In addition, a large number of New Zealand lines were selected, particularly those with known insect or nematode resistance. Material with good general agronomic performance, such as advanced breeding lines and 
New Zealand clover cultivars, were also included. The screening focused predominantly on white clover (246 lines) but also included five lucerne, five birdsfoot trefoil (Lotus corniculatus), seven red clover (Trifolium pratense), six lotus major (Lotus pedunculatus) and six caucasian clover (Trifolium ambiguum) lines.

The legume evaluation was conducted on four dairy and three sheep/beef commercial farms spread over approximately $200 \mathrm{~km}$ north-south (Wellsford-Hamilton) and $130 \mathrm{~km}$ east-west (Bay of Plenty-Western Waikato), with three sites in the heavily infested area between the Kaimai Range and Hamilton. The farms typically exhibited abundant damage to clover leaves from CRW adults and high numbers of larvae were present in the soil.

At the Wellsford dairy farm, 147 lines were planted while one of two sets of 120 lines were planted at the six other sites. Included in these lines was a standard set of 27 white clover lines (predominantly New Zealand cultivars and advanced breeding lines) and the 29 non-white clover lines. Lines were replicated five times at each site except at Wellsford (four reps) and a plot consisted of a $1-\mathrm{m}$ row of 10 plants, spaced at $100-\mathrm{mm}$ intervals. Inter-row space was $1 \mathrm{~m}$ in each direction. Unseasonally dry conditions shortly after planting (September 1998) caused complete establishment failure at one site and an alternative site was planted to replace it (May 1999).

Seed from each line was pre-germinated on moist filter paper prior to sowing into $125-\mathrm{ml}$ root trainers filled with potting mix, which contained slow release fertiliser. Plants were grown in a glasshouse for 10-12 weeks over winter, hardened off outside for 2 weeks and then planted in the field. While in the glasshouse, plants were cut back twice to stimulate their development, and were also cut back 1-2 days prior to planting in the field. The field sites were blanket sprayed with Dicamba to remove any resident legumes 3 months prior to planting with follow-up spot-sprays 4-5 weeks prior to planting. The plants were lifted from the root trainers with the potting mix attached and planted in prepared holes, to minimise disturbance to the roots.

Plants were evaluated at variable intervals (determined by rotation length) prior to grazing, and visually scored for leaf damage and the amount of shoot material present. A growth score was noted every time, but generally low levels of leaf damage resulted in few leaf damage scores being noted. While it is acknowledged that root feeding by CRW causes more serious damage to the clover plant than foliage feeding by adults, no non-destructive evaluation method for root damage was available. Root damage ultimately has an effect on shoot production and it was considered that this would be reflected in the growth score.
Soil pest fauna was sampled at Wellsford in August 1999, soil cores (100 mm diameter x $100 \mathrm{~mm}$ deep) were taken from just outside the trial area and smaller cores $(75 \mathrm{~mm}$ diameter $\times 100 \mathrm{~mm}$ deep) were taken from over surviving specimens of planted clovers. Samples were hand sorted in the field and all macro soil-dwelling stages of pest species recorded.

\section{Data analysis}

Lines were planted out at one, two, three or seven different sites, which made comparisons between them difficult, especially between those that were not planted together at a single site. To make some valid comparisons between all lines, the scores of individual lines were scaled relative to the average score for the 56 standard lines planted at each site. For lines planted on multiple sites, the average relative score was used.

\section{Results and discussion}

The aim of the legume evaluation reported here was to identify lines with good performance characteristics under high CRW loading. Potentially four types of plant-pest interactions could be anticipated, non-host, resistance, tolerance and susceptibility interactions. A non-host interaction exists when the pest does not feed on the plant species with the exception of maybe a few test bites. A host is resistant to a pest, if the pest in the presence of an adequate supply of appropriate plant material is unable to sustain itself. A host is tolerant to the pest when it can maintain a reasonable level of productivity in the presence of a large sustainable population of the pest. A host plant is said to be susceptible if it succumbs to the pressure put on it by the pest.

Of the four possible interactions, it was anticipated that the non-Trifolium species would be non-hosts and that amongst the Trifolium species there would be variable levels of susceptibility and tolerance. Resistance was not anticipated, as it generally requires a very highly developed dependent interaction between a single host plant species and a pest species. The host plant range for CRW covers a number of different species within the Trifolium genus (Gerard et al. 1999) and CRW adults are highly mobile feeders, characteristics not likely to result in a highly dependent interaction with a single host species. Also, white clover is an outcrossing species, which decreases the chances of expression of resistance genes.

None of the lucerne, birdsfoot trefoil and lotus major plants showed significant CRW foliar damage at any time during the trial (Figure 1); although some minor CRW damage (most likely test bites) was 
Figure 1 The relationship between CRW damage and legume productivity at seven trial sites (scores relative to the average score of the set of 56 standard lines).

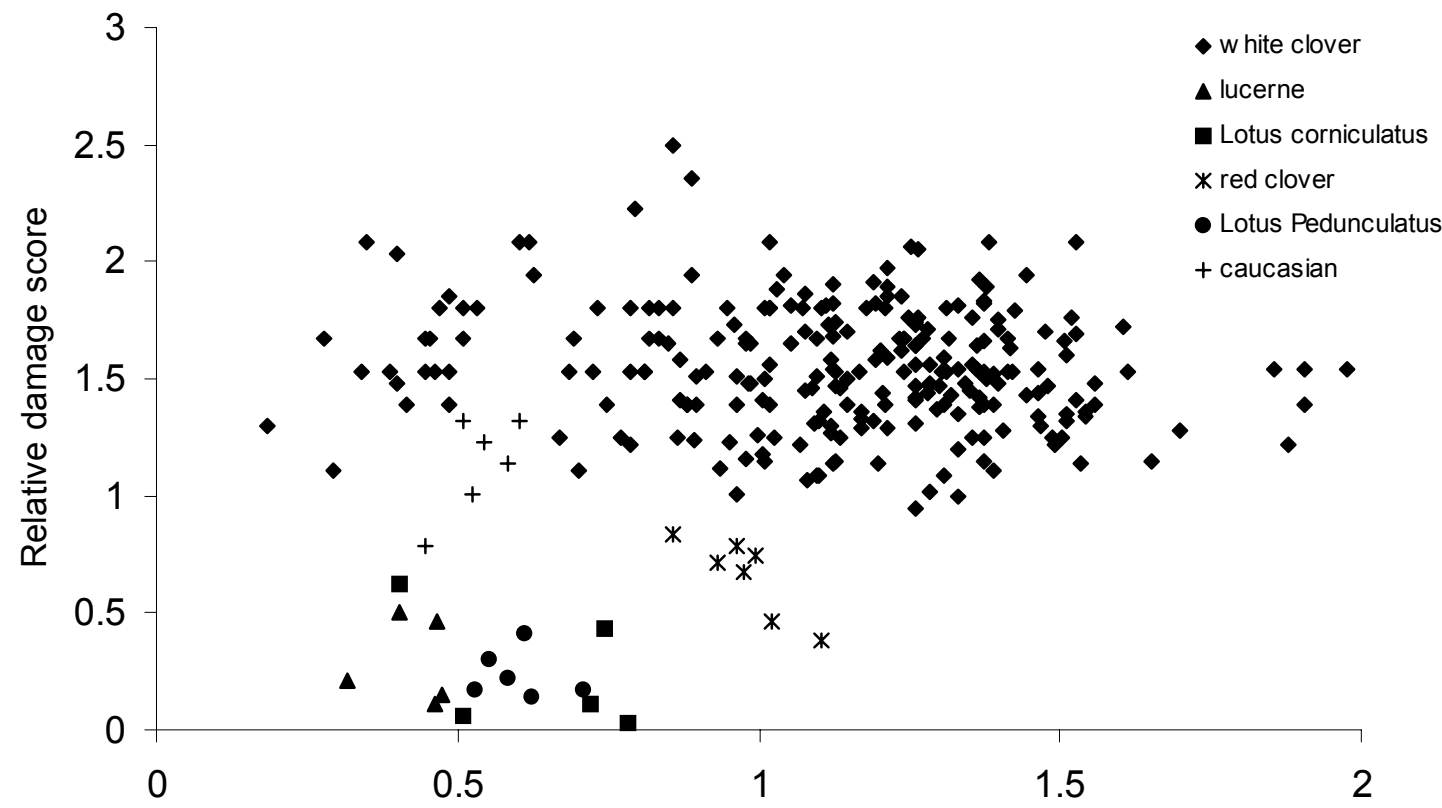

Relative growth score

Figure $\llbracket 2$ The relationship between CRW damage and legume productivity at Wellsford (scores relative to the average score of the set of 56 standard lines).

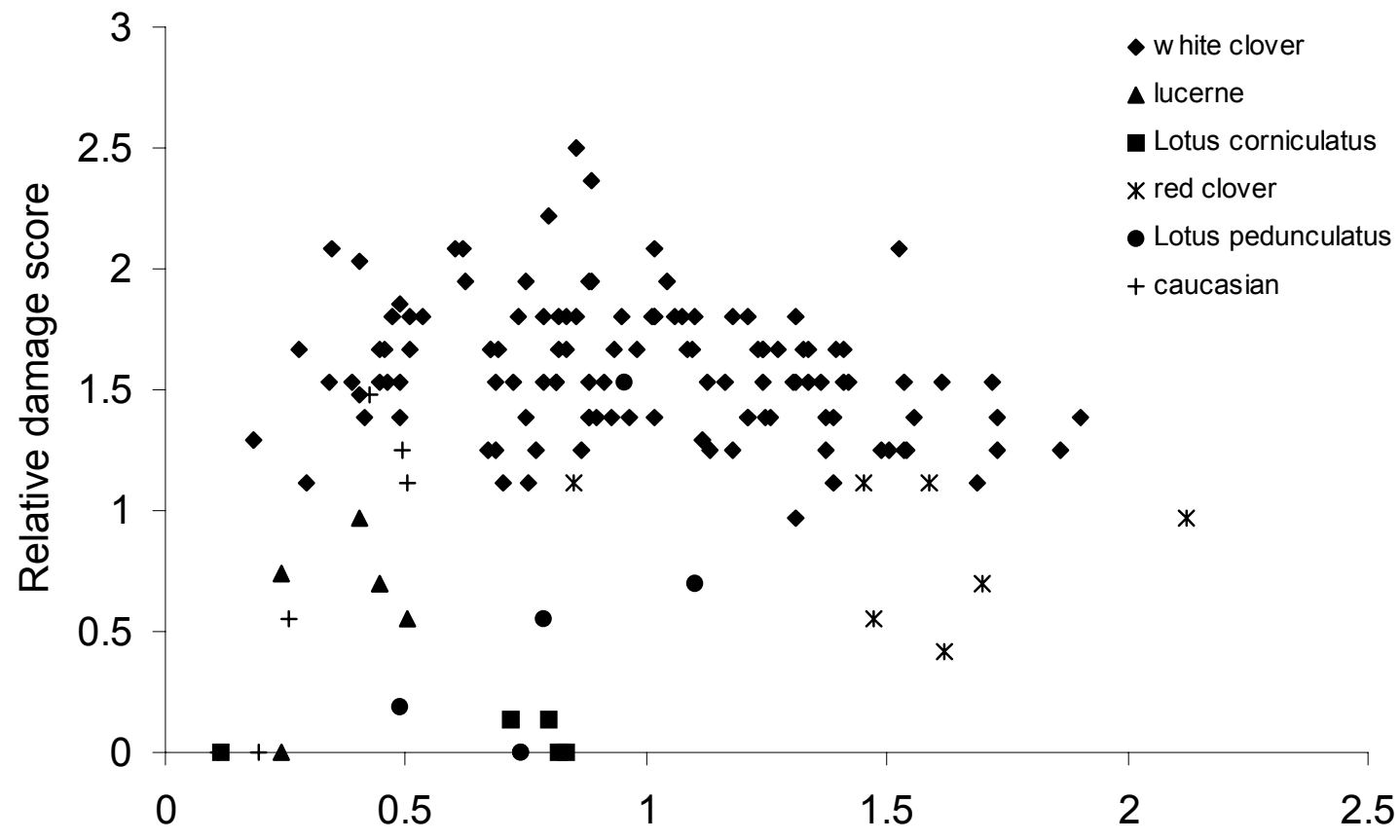

Relative growth score 
observed, the scores were not significantly different from zero. The lack of significant CRW damage, especially when compared with white clover, supports earlier observations that the non-Trifolium species are non-hosts to the CRW (Gerard et al. 1999).

Foliar CRW damage was observed on Trifolium species (white clover, red clover and caucasian clover). At Wellsford, high summer rainfall allowed high CRW populations to build up and major foliar CRW damage occurred over summer. Damage to caucasian clover was high relative to the amount of shoot material present. This was probably because, in the first 1-2 years after germination, caucasian clover invests more energy in developing a root system than in developing a shoot system and this was reflected in low growth scores. Red clover was a less-preferred host than either white clover or caucasian clover. This was reflected particularly in its excellent performance under high CRW pressure at Wellsford (Figure 2) with a relative low damage score relative to the growth score. However, red clover is not competitive with white clover agronomically (Figure 1), dependence on a single taproot exposes its structural weakness in an intensive dairy grazing situation. Damage to red clover taproots from stock treading generally results in the plant death after one or two winter seasons.

A major problem with evaluations such as the one reported here is a dependence on the natural build up of the stress factor. Two to 3 years are required for the CRW population to build up to damaging levels from a non-detectable base. It is not practical to inoculate test sites with CRW eggs. Only $2-3 \%$ of the eggs deposited in the field successfully develop into first instars (Willoughby, pers. comm.). Since the start of the trial, the importance of adequate soil moisture for a rapid build up of CRW populations has become better understood (Eerens et al. 1998). Unfortunately, summer moisture conditions were sufficient only at Wellsford for maintaining CRW populations. Here, CRW made up around $96 \%$ of the soil pest fauna with larval densities under individual plants averaging around 780 (range $450-1560)$ larvae $/ \mathrm{m}^{2}$. These numbers were high enough to cause serious damage to clover plants and the high rate at which plant population densities began to decrease was evidence of this (data not shown). In selecting lines for further evaluation and examination, the results from Wellsford were given most consideration. The other sites mainly contributed information on which lines were top performers agronomically.

\section{Where to from here?}

The lines selected from the evaluation were planted out at the Ruakura Research Centre and the Kerikeri
Research Station where they will be subjected to closer scrutiny to identify the characteristics contributing to their perceived tolerance to CRW. At Ruakura, the evaluation method has been refined to implement the conditions necessary for clover plants to be subjected to high pest pressure from an early stage. Strip spraying has substituted the blanket spray to ensure a CRW population remains close to the new plantings and irrigation has been used to ensure that soil moisture is adequate for optimal CRW development. CRW population densities are being examined on a regular basis and are linked to critical plant events.

\section{Conclusion}

The potential of CRW to devastate clover was observed at Wellsford, and the other sites demonstrated the relationship between CRW damage and summer moisture conditions. An encouraging level of variation was observed amongst white clovers in response to the presence of CRW. While no single line conclusively demonstrated either resistance or tolerance, it was possible to select a group of 23 lines from the original 275 lines and these are currently being subjected to detailed examination under more controlled conditions to identify features that contribute to high production levels under high CRW population density.

\section{ACKNOWLEDGEMENTS}

The New Zealand Dairy Board, Meat New Zealand, WoolPro and the Game Industry Board funded most of this research. The evaluation at the Warkworth site was funded by the Foundation for Research Science and Technology. The authors thank George Brier, Dr Jim Crush, Shirley Nichols and Li Ouyang for helping with the planting. John Waller provided useful comments on the validity of the statistical methods used. A thank you goes also to Stuart Bay, Tony Drabble, Simon Garrett, Malcolm Harding, Keith Holmes, Rod Nicols, Frank Park, and Brett Prendergast for managing the evaluation sites as part of the farm operations.

\section{REFERENCES}

Barratt, B.I.P.; Barker, G.M.; Addison, P.J. 1996. Sitona lepidus Gyllenhal (Coleoptera: Curculionidae), a potential clover pest new to New Zealand. New Zealand Entomologist 19: 23-30.

Eerens, J.P.J.; Willoughby, B.; Kettlewell, F.; Hardwick, S.; Bay, S. 1998. The clover root weevil in northern pastures: on-farm observations of its impact on white clover. Proceedings of the New Zealand Grassland Association 60: 287-290. 
Gerard, P.J.; Addison, P.J.; Hardwick, S.; Willoughby, B.E. 1999. Establishment of the invader: insights into life history and biology of Sitona lepidus in the Waikato region of New Zealand. Proceedings of the 7th Australasian Conference on Grassland Invertebrate Ecology: 43-51.

Murray, P.J. 1996. Evaluation of a range of varieties of white clover for resistance to feeding by weevils of the genus Sitona. Plant Varieties and Seeds 9: 914.

Phillips, C.B.; Goldson, S.L.; Reimer, L.; Kühlmann, U. 2000. Progress in the search for biological control agents of clover root weevil, Sitona lepidus (Coleoptera: Curculionidae). New Zealand Journal of Agricultural Research 43: 541-547. 